\title{
Percutaneous pulmonary valve implantation - state of the art and Polish experience
}

\author{
Elżbieta K. Biernacka ${ }^{1}$, Witold Rużyłło², Marcin Demkow ${ }^{3}$ \\ ${ }^{1}$ Department of Congenital Heart Diseases, Institute of Cardiology, Warsaw, Poland \\ ${ }^{2}$ Institute of Cardiology, Warsaw, Poland \\ ${ }^{3}$ Department of Coronary and Structural Heart Diseases, Institute of Cardiology, Warsaw, Poland
}

Adv Interv Cardiol 2017; 13, 1 (47): 3-9

DOI: https://doi.org/10.5114/aic.2017.66180

\begin{abstract}
A bstract
Percutaneous pulmonary valve implantation (PPVI) is a relatively new method of treating patients with right ventricular outflow tract (RVOT) dysfunction after surgical repair of congenital heart disease. Since its introduction in 2000 by Bonhoeffer, more than ten thousand PPVI procedures have been performed worldwide. Indications for PPVI have been adapted from those accepted for surgical intervention. Two types of valves are being used: Melody Medtronic available in diameters $16 \mathrm{~mm}$ and $18 \mathrm{~mm}$ and the family of Edwards SAPIEN valves 23, 26 and 29. The procedure has been shown to be feasible and safe when performed in patients with full pulmonary conduit dysfunction and in selected cases of patched RVOT. The low complication rate and the reduced number of open-chest re-interventions over a patient's lifetime are among the main advantages of the procedure. The most important problem responsible for late mortality and reinterventions is infective endocarditis. Size restrictions of the currently available valves limit deployment in the majority of patients with a wide RVOT. Newer devices are being developed to make these patients suitable for PPVI. A literature review, Polish experience and results of PPVI performed in 66 patients in the Institute of Cardiology in Warsaw are briefly reported.
\end{abstract}

Key words: percutaneous valve implantation, pulmonary valve, congenital heart defects.

\section{Introduction}

The estimated prevalence of congenital heart diseases (CHD) in adulthood is about 1 per 150 people and is growing because of advances in pediatric cardiology and cardiac surgery. Half of adult patients with CHD have undergone surgery in the past. Twenty percent of newborns with CHD have a right ventricular outflow tract (RVOT) defect such as tetralogy of Fallot, pulmonary atresia or truncus arteriosus, transposition of great arteries, common arterial trunk, and others, requiring surgical reconstruction with the use of a patch, bioprosthetic valve or valved conduits [1, 2]. Homograft implantation is also a part of the Ross procedure for aortic valve disease. Long-term durability of surgical interventions depends on patient age, heart defect, the type of tissue or material utilized and the type of the operation. Patients after RVOT reconstruction using a transannular patch usually have pulmonary regurgitation immediately after the operation. Degeneration of biological material of bioprostheses and valved conduits results in progressive RVOT dysfunction, including pulmonary stenosis (PS) and regurgitation (PR), thought repeat surgical interventions over the lifetime are frequent in this group of patients [3-5].

The severity of PR increases over time due to increase of RV stroke volume, enlargement of regurgitant orifice and longer duration of diastole. After RVOT correction with a patch, significant PR is observed in $48 \%$ of patients directly after the operation and in $85 \%$ of patients 2 years later [6]. In patients after a correction using a valved homograft significant RVOT dysfunction (PR and/or PS) is observed in $50-55 \%$ of patients during 10 years after the first correction and 5-6 years after the second procedure [6].

For many years, pulmonary regurgitation was considered to be benign because right ventricular volume overload can be well tolerated for a long time. Now it is known that patients with PR are at risk for heart failure, arrhythmia and sudden cardiac death. At age 20 years, only $6 \%$ of the patients have symptoms, but at the age of 40 years the percentage of symptomatic patients in-

\section{Corresponding author:}

Prof. Elżbieta K. Biernacka MD, PhD, Department of Congenital Heart Diseases, Institute of Cardiology, 42 Alpejska St, 04-628 Warsaw, Poland, phone: +48223434634, e-mail: k.biernacka@ikard.pl

Received: 7.01.2017, accepted: 11.01.2017. 
creases to almost $30 \%$. The risk of death follows the development of symptoms in a short time [7]. Appearance of symptoms (fatigue, edema, arrhythmia) indicates that the compensatory mechanisms of the right ventricular myocardium fail and the dysfunction is irreversible. Optimal timing of pulmonary valve replacement is a matter of continuing debate because factors affecting long-term outcomes and risk factors for irreversibility of RV damage are not known [8-10].

Current recommendations for surgical pulmonary valve replacement include significant PR (pulmonary regurgitation fraction (PRF) $\geq 25 \%$ ) or/and significant PS (RV/ systemic pressure $>2 / 3$ ), RV enlargement (EDVI $\geq 160 \mathrm{ml}$ $\mathrm{m}^{2}, \mathrm{ESVI} \geq 80 \mathrm{ml} / \mathrm{m}^{2}$ ), RV contractility impairment (RVEF $\leq$ $47 \%$ ), decreased end-diastolic LV volume (LVEDVI $\leq 65 \mathrm{ml}$ $\mathrm{m}^{2}$ ) and/or the presence of symptoms particularly when pharmacological treatment is necessary. Exercise cardiopulmonary function deterioration, QRS duration > $140 \mathrm{~ms}$, increased NT pro-BNP level, and restrictive RV physiology (late diastolic forward flow through the pulmonary valve) are considered additionally, but none of above-mentioned factors is sensitive enough to predict RV function restoration. Nevertheless, there are many data showing that we operate too late and then a more aggressive approach has been suggested (Table I) [2, 11-13]. On the other hand, surgical intervention performed too early may lead to numerous reoperations or interventions over the lifetime, each of it connected with higher risk $[14,15]$.

\section{Percutaneous pulmonary valve implantation}

Since the first percutaneous pulmonary valve was implanted by Bonhoeffer et al. in 2000 [16], more than
10 thousand such procedures have been performed in 200 centers in 35 countries (154 centers in Europe). Two kinds of valves are being used: Melody Medtronic and Edwards SAPIEN.

The Melody valve, first used by Bonhoeffer, received the CE Mark \& Health Canada Approval in 2006 and US FDA Approval in 2010. In 90\% of patients all over the world the Melody valve was used. The valve consists of a bare-metal platinum-iridium stent (CP stent, NuMED, Inc., Hopkinton, New York) and a manually sewn valved segment of bovine jugular vein. The device is available in diameters 16 and $18 \mathrm{~mm}$. Before implantation the device is crimpled over a balloon-in-balloon catheter and mounted on a 18, 20, or $22 \mathrm{~mm}$ delivery system (Ensemble, Medtronic, Minneapolis, USA). After being introduced into the pulmonary artery the stent is uncovered and internal (the valve can still be repositioned at this step) and external balloons are inflated, resulting in the valve deployment. The main limitation of the Melody valve is its relatively small size [17].

In 2006 Edwards-Cribier valve, having been used in the aortic position, was implanted in the RVOT and gave a beginning to a new family of Edwards transcatheter pulmonic valves [18]. The Edwards SAPIEN valves (Edwards Lifesciences, Irvine, California) are trileaflet bovine pericardial tissue valves hand-sutured in a balloon-expandable, radiopaque, stainless steel stent, available in 2 diameters: 23 and $26 \mathrm{~mm}$. The next generation Edwards SAPIEN XT valve has a cobalt chromium frame, available also in diameter $29 \mathrm{~mm}$, and is the first transcatheter heart valve approved for pre-stented transannular patches. SAPIEN3, equipped with an outer pericar-

Table I. Recommendations for surgical pulmonary valve replacement in asymptomatic patients

\begin{tabular}{|c|c|c|c|c|}
\hline Parameter & $\begin{array}{c}\text { ESC } \\
\text { Eur Heart J } \\
\text { 2010; 31: 2915-57 }\end{array}$ & $\begin{array}{c}\text { AHA } \\
\text { J Am Coll Cardiol } \\
\text { 2008; 52: e143-263 }\end{array}$ & $\begin{array}{c}\text { CCS } \\
\text { Can J Cardiol } \\
\text { 2010; 26: e80-97 }\end{array}$ & $\begin{array}{c}\text { New (proposed) } \\
\text { Circulation } \\
\text { 2013; 128: 1855-7 }\end{array}$ \\
\hline RVEDVi $\left[\mathrm{ml} / \mathrm{m}^{2}\right]$ & $>160$ & $\geq$ Moderate & $>170$ & $>140-150$ \\
\hline RVESVi $\left[\mathrm{ml} / \mathrm{m}^{2}\right]$ & $?$ & $?$ & $?$ & $>80$ \\
\hline RV dysfunction & Progressive RV dysfunction & $\geq$ Moderate & $\geq$ Moderate & RVEF $<47 \%$ \\
\hline PS & $\mathrm{PG} \geq 80 \mathrm{~mm} \mathrm{Hg}$ & $\begin{array}{c}\mathrm{PG} \geq 50 \mathrm{~mm} \mathrm{Hg} \text { or } \mathrm{RV} / \mathrm{LV} \\
\text { pressure ratio } \geq 0.7\end{array}$ & $\begin{array}{l}\text { RV/systemic systolic } \\
\text { pressure } \geq 2 / 3\end{array}$ & $\begin{array}{l}\mathrm{RV} / \text { systemic systolic } \\
\text { pressure } \geq 2 / 3\end{array}$ \\
\hline PR & Severe & Severe & Free & $\begin{array}{l}\geq \text { Moderate } \\
(P R F \geq 25 \%)\end{array}$ \\
\hline QRS duration [ms] & $>180$ & $?$ & $?$ & $\geq 140$ \\
\hline Arrhythmia & Sustained AT or VT & $\begin{array}{c}\text { Symptomatic or sustained } \\
\text { AT or VT }\end{array}$ & AT or VT & Sustained tachyarrhythmia \\
\hline CPET & Decrease & $?$ & $?$ & $<60 \%$ predicted \\
\hline Other & & Significant VSD, AR & Significant VSD & $\begin{array}{c}\text { LVEF }<55 \%, \text { RV/LV EDV }>2 \\
\text { significant VSD, AR, } \\
\text { aortic dilation }\end{array}$ \\
\hline
\end{tabular}

ESC - European Society of Cardiology, AHA - American Heart Association, CCS - Canadian Cardiology Society, RVEDVi - right ventricular end-diastolic volume index, $R V E S V$ - right ventricular end-systolic volume index, RV - right ventricle, RVEF - RV ejection fraction, PS - pulmonary stenosis, PG - pulmonary gradient, $L V$ - left ventricle, $P R$ - pulmonary regurgitation, PRF - pulmonary regurgitation fraction, AT - atrial tachyarrhythmia, VT - ventricular tachycardia, CPET - cardiopulmonary exercise test, VSD - ventricular septum defect, $A R$ - aortic regurgitation, EDV - end-diastolic volume. 
dial skirt, is designed to minimize perivalvular leak. The valve, manually crimped with a specialized tool, is implanted using the Retroflex-3 or Novaflex delivery system (Edwards Lifesciences) consisting of a guiding catheter and a single-balloon catheter [19-22].

\section{Indications for percutaneous pulmonary valve implantation and patient selection}

Initially percutaneous pulmonary valve implantation (PPVI) was performed only in patients with a dysfunctional full conduit in the RVOT. Extended application of this method was proposed by Bonhoeffer's group in 2009 [23]. After prestenting with a metal stent, the Melody valve was implanted in the stenotic patched RVOT. In 2013 we published our experience with PPVI (Melody - 5 patients, SAPIEN 18 patients) in patients with significant pulmonary regurgitation after previous surgical repair with a transannular patch. In all patients prestenting with a bare metal stent was performed to prepare a stiff landing zone for the valve. In case of borderline dimension of RVOT prestenting was performed 2 months before valve implantation [24].

Extended indications for PPVI are limited by RVOT dimensions and precisely determined anatomical conditions, in particular, the location of coronary arteries. Detailed preprocedural assessment is crucial for successful PPVI. Echocardiography and cardiac magnetic resonance (CMR) imaging are important tools for assessment of right and left ventricular function and diameters [25]. The severity of RVOT gradient is estimated by Doppler recordings. Pulmonary regurgitation volume, PRF and RVOT morphology and size are assessed by CMR. In some cases computed tomography may be necessary to obtain ana- tomical imaging of RVOT and coronary arteries. Pre-procedural assessment should be complemented by precise analysis of sequential ECGs and CPET results [26].

\section{Procedure}

Percutaneous pulmonary valve implantation is performed under general anesthesia through the femoral, jugular, or subclavian veins. Cardiac catheterization with assessment of the right heart, pulmonary and aortic pressures precedes each implantation. Right ventricular outflow tract angiograms in at least two orthogonal projections allow one to assess its dimensions. To enable precise measurements and estimation of the minimal outflow diameter and balloon waist position, low pressure, $30 \mathrm{~mm}$ diameter/4 $\mathrm{cm}$ balloon inflations (PTS-X Sizing Balloon Catheter, NuMED Canada Inc.) are performed. To rule out any potential compression of the coronary arteries by the implanted stent, simultaneous selective left and right coronary angiography should be performed during balloon inflation in each patient. Valve implantation is preceded by routine presenting with a bare metal stent [27]. Procedural success reaches $94-98 \%$ (Table II) [21, 28-34]. Hospitalization time usually does not exceed 4-5 days. Immediately after the discharge patients were fit to work or able to go back to school.

Several centers have consistently reported a low periprocedural complication rate (3-6\%). Among procedural complications coronary artery compression is the most important and catastrophic complication, strongly related to early procedural mortality. Due to variability in coronary anatomy approximately $5 \%$ to $6 \%$ of candidates for PPVI are at risk for coronary compression after

Table II. Results of percutaneous pulmonary valve implantation - literature review

\begin{tabular}{|c|c|c|c|c|c|c|c|c|}
\hline Author & Valve & $\begin{array}{c}\text { No. of } \\
\text { patients }\end{array}$ & $\begin{array}{c}\text { Mean } \\
\text { age } \\
\text { [years] }\end{array}$ & $\begin{array}{c}\text { Procedure } \\
\text { success } \\
(\%) \\
\end{array}$ & $\begin{array}{l}\text { Follow-up } \\
\text { [years] }\end{array}$ & $\begin{array}{c}\text { Freedom from } \\
\text { reintervention } \\
\text { (\%) }\end{array}$ & $\begin{array}{c}\text { IE } \\
\text { No. of } \\
\text { patients }\end{array}$ & Improvement \\
\hline $\begin{array}{l}\text { Cheatham, USA, } \\
2015\end{array}$ & Melody & 170 & 19 & NA & 4.5 & 76 & 3 & $\begin{array}{l}\text { Exercise capacity, NYHA } \\
\text { functional class }\end{array}$ \\
\hline $\begin{array}{l}\text { Borik, Canada, } \\
2015\end{array}$ & Melody & 51 & 20 & NA & 4.5 & 68 & 1 & $\begin{array}{l}\text { RV size and maximum oxygen } \\
\text { consumption }\end{array}$ \\
\hline $\begin{array}{l}\text { Armstrong, USA, } \\
2014\end{array}$ & Melody & 101 & 20 & 98 & 1.0 & 97 & 3 & $\begin{array}{l}\text { NYHA functional class, } \\
\text { tricuspid regurgitation }\end{array}$ \\
\hline $\begin{array}{l}\text { Butera, Italy, } \\
2013\end{array}$ & Melody & 63 & 24 & 94 & 2.5 & 92 & 2 & RVEDV, RVEF, RVESV \\
\hline $\begin{array}{l}\text { Biernacka, Poland, } \\
2015\end{array}$ & $\begin{array}{l}\text { Melody } \\
\text { SAPIEN }\end{array}$ & $\begin{array}{l}40 \\
20\end{array}$ & 25 & 93 & 1.7 & 90 & 4 & $\begin{array}{l}\text { NYHA functional class, RVEDV, } \\
\text { RVEF, maximum oxygen } \\
\text { consumption }\end{array}$ \\
\hline $\begin{array}{l}\text { Lurz, UK, } \\
\text { 2008, } 2011\end{array}$ & Melody & 155 & 21 & 95 & 2.3 & $93-70$ & 5 & $\begin{array}{l}\text { RVEDV, RVEF, maximum oxygen } \\
\text { consumption }\end{array}$ \\
\hline $\begin{array}{l}\text { Kenny, USA, } \\
2011 \text { (COMPASSION) }\end{array}$ & SAPIEN & 36 & 30 & 97 & 0.5 & 97 & 0 & NYHA functional class, RVEDV \\
\hline $\begin{array}{l}\text { Haas, Germany, } \\
2015\end{array}$ & SAPIEN & 22 & 22 & 90 & 0.5 & NA & 0 & NYHA functional class \\
\hline
\end{tabular}

IE - infective endocarditis, NYHA - New York Heart Association, RVEDV - right ventricular end-diastolic volume, RVEF - right ventricular ejection fraction, RVESV right ventricular end-systolic volume. 
metal stent expansion in RVOT [35]. In case of any doubt about the risk of coronary compression the procedure should be abandoned. Homograft rupture is a relatively frequent complication in cases with calcified conduits or due to aggressive dilatations of the oversized balloon. In hemodynamically stable patients, implantation of covered stents may be an alternative to surgical treatment. Stent migration during valve implantation in patients with the borderline size of RVOT was reported when the valve implantation was performed in a single procedure with the stent implantation. In patients with a relatively wide RVOT without a waist after pre-stenting, the valve implantation should be postponed by at least 2 months to allow proper fixation of the stent. Tissue growing into the stent provides a reliable landing zone for the valve and minimizes the chance of stent migration during the valve implantation. Thus, a two-step procedure in patients with borderline size of the outflow tract is recommended. Tricuspid valve damage during maneuvers with the delivery system was reported [36].

\section{Early and medium-term results}

Several groups have shown favorable early results after PPVI (Table II) [21, 28-34]. Right ventricular outflow tract gradient normalization and PR resolution were achieved in the vast majority of patients after successful implantation. In isolated cases moderate PR or residuary pulmonary gradient across the valve were observed. In a short follow-up (1 ${ }^{\text {st }}$ month) improvement in systolic RV volumes and function as well as left ventricular ejection fraction has been reported. Moreover, NYHA class and maximum oxygen consumption improvement were observed predominantly in patients with PS [33].

Further observations confirm that the results are stable in a few years but do not show subsequent improvement, indicating that changes in RV end-diastolic volume and RV ejection fraction result from normalization of hemodynamic conditions, not structural myocardial remodeling. Lack of continuous improvement beyond the $1^{\text {st }}$ month may be related to late performance of the intervention [33].

Data from 3 prospective multicenter studies (300 patients) with transcatheter Melody valve implantation conducted in Canada and Europe has showed recently that significant baseline tricuspid regurgitation (TR), often seen in patients with RVOT dysfunction, was improved in $65 \%$ of patients. Acute reduction of TR persisted over 5 years of follow-up. This finding may extend indications for those patients with RVOT dysfunction suitable for PPVI who were referred for surgery because of concomitant TR [37].

\section{Late complications}

Freedom from reintervention after PPVI depends on follow-up time and is about $90 \%, 80 \%$ and $70 \%$ respectively at 1,2 and 4 years observation. Five-year freedom from explant is about 92\% [28]. The main reason for reintervention or explant is high post-procedural pulmonary gradient, stent compression or stent fracture.

Valve stent fracture was reported in up to $34 \%$ of patients after Melody valve implantation not preceded by bare metal stent implantation (prestenting). Risk factors of stent fracture include younger age, higher pre- and post-procedural RVOT gradient, smaller size of conduit and valve position directly under the sternum. Stent fractures were significantly reduced $(16.7 \%)$ when pre-stenting became a routine procedure [38].

At present, the most important problem responsible for late mortality and reintervention/explantation in patients after PPVI is infective endocarditis (IE). The risk of IE is estimated at $2.4(0.34-6.03) \%$ per patient/year [3942]. Moreover, IE occurs more frequently after PPVI than surgical pulmonary valve replacement. Two large studies comparing the incidence and outcomes of right-sided endocarditis in patients after surgical or PPVI showed 4.5-fold higher risk of IE after a percutaneous procedure $[40,41]$. Several factors explaining this remarkable difference have been discussed. One of the main differences between transcatheter and surgical valve replacement is possible valvular damage before percutaneous implantation during crimping and during balloon expansion, whereas surgical prostheses are placed directly in the RVOT without any manipulation [43]. There is a higher incidence of reported endocarditis in patients after Melody valve implantation compared with SAPIEN. This may be explained by the much higher distribution of the Melody valve. Yet, the histological lesions observed on traumatized leaflets of the Melody valve after crimpling might constitute a possible target for bacterial germs. Such lesions were not observed in pericardial valves [44]. It is suggested that there is a higher incidence of endocarditis in patients after the procedure performed from a jugular approach; however, early IE after PPVI is extremely rare. Among other risk factors of IE the most important are poor dental hygiene, unprotected dental care, piercing, tattoo and nail biting. Male sex seems to be a predisposing factor probably due to more frequent noncompliance with prophylactic indications. Some authors suggest suboptimal hemodynamic results (residual gradient, eccentric turbulence, pockets due to incomplete apposition, thrombus formation, asymmetric or incomplete opening with redundancy of leaflet tissue) as possible risk factors of IE. Prior IE increases relative risk to 3.3 [42].

Modified Duke criteria should be used for IE diagnosis, which is usually difficult. Blood cultures are usually negative because of frequent prehospital antibiotic therapy. Transthoracic ECHO (TTE) is negative in up to $70 \%$, but TTE plus TEE is positive in $75 \%$ of affected patients. Other modern techniques should be used in unclear cases such as 18F-FDG PET/CT, leukoscan imaging and/or intracardiac ECHO. 
Though IE is the main cause of the late mortality, the outcome spectrum after PPVI is wide. Medical therapy without the need for reintervention may be successful in a significant proportion of patients. Reintervention or valve explantation was performed in $21 \%$ of affected patients. Emergency operations were reported incidentally $[42,45]$.

Prevention includes the avoidance of a hazardous lifestyle, good body hygiene, dental care, avoidance of skin lesions and antibiotic prophylaxis prior to foreseeable episodes of significant bacteremia. Long-term anticoagulation or antiplatelet therapy was suggested to reduce the incidence of initial thrombus formation in an area of endothelial damage which could be the location of infective vegetations after transient bacteremia [43].

\section{Own experience}

The first PPVI in Poland was performed in December 2008 in the Institute of Cardiology in Warsaw-Anin [46]. It was the first percutaneous valve implantation in Poland. Now, PPVIs are being performed in our and other centers: the Silesian Center for Heart Diseases in Zabrze (Melody - 24, SAPIEN - 2) and Polish Mother's Memorial Hospital Research Institute in Lodz (Melody - 25). Three centers have recently started performing the procedure using the Melody valve (University Hospital of Lord's Transfiguration, Poznan - 4, Copernicus, Gdansk - 1, The Children's Memorial Health Institute, Warsaw - 1).

In the Institute of Cardiology in Warsaw-Anin we performed 66 procedures. The Melody valve was used in 45 and Edwards SAPIEN in 21 patients, with $92.5 \%$ success (5 unsuccessful implantations). There was no periprocedural mortality. In 2011 we extended indications for PPVI for patients with a native or patched RVOT [24]. In most of these patients the procedure of SAPIEN Edwards valve implantation was preceded by metal stenting 2 months earlier. Early and long-term observations show an excellent outcome with $100 \%$ freedom from reintervention in 1-year and $88 \%$ in mean 4.5-year (1 month-8 years) observation. Hemodynamic parameters of RV function (RVEDVi and RVEF) improve in 1-month follow-up and remain constant during mid- term observation [32]. Exercise capacity enhances in one year observation [47]. Reintervention, valve explantation and late mortality ( 2 cases) were associated with infective endocarditis (about 2\% patient/year).

\section{Future of percutaneous pulmonary valve implantation}

Indications for PPVI are restricted to patients with RVOT diameter up to $22 \mathrm{~mm}$ for the Melody valve and up to $27 \mathrm{~mm}$ for the SAPIEN Edwards valve. The majority of patients ( $>80 \%$ ) who are potential candidates for pulmonary valve implantation have large patch-augmented RVOTs. There is worldwide interest in developing new devices (valves or right ventricular outflow tract reducers) and/or techniques to make these patients suitable for PPVI.

Double or triple metal stent implantation (Russian doll technique) preceding valve insertion may be performed in selected cases. The use of two Melody valves implanted in both pulmonary arteries was reported in a single patient [48]. In 2010 a new self-expandable transcatheter pulmonary valve (the Native Outflow Tract device, Medtronic Inc., Minneapolis, MN, USA) was successfully implanted in a 42-year-old patient with PR [49]. Prototyping models of the valve were created on the basis of computed tomography to fit the patient's RVOT anatomy. The valve (Harmony TM) is made with porcine pericardium and a self-expanding nitinol stent characterized by hourglass geometry (i.e. larger diameters at the proximal and distal end, smaller diameters in the central portion holding the valve) which should help the stability of the device in a large RVOT. In April 2016 Medtronic announced the first clinical data of the Harmony Transcatheter Pulmonary Valve implanted in 20 patients. The early feasibility study is a non-randomized prospective study in 3 sites in the United States and Canada. Sixmonth follow-up showed positive early outcomes [50]. Other self-expandable devices (Venous P Valve; Medtech, Shenzhen, China and The Lotus Valve System, Boston Scientific Corporation, Natick, MA, USA) are under investigation.

Right ventricular outflow tract reducers were proposed by Boudjemline et al., who designed and developed in experimental studies several versions of a self-expandable stent, forming a covered double cylinder with external diameters $30-40 \mathrm{~mm}$ and the internal diameter which enables implantation of a valved stent [51]. Recently, Edwards described an Altera Device, one size $(40 \times 45 \mathrm{~mm})$ nitinol self-expanding covered stent providing a rigid landing zone for SAPIEN S3 $29 \mathrm{~mm}$, suitable for RVOT diameters up to $38 \mathrm{~mm}$ [52]. In some cases hybrid procedures with mutual collaboration from cardiac surgery and interventional cardiology are proposed [53]. Surgery reducing RVOT dimensions and transapical pulmonary valve implantation have been performed by Polish surgical-interventional teams recently.

\section{Conflict of interest}

E. K. Biernacka - coordinator, PREMIER (Pulmonic Valve Replacement Multi-discipline EMEA Registry), Edwards Lifesciences, W. Rużyłło declares no conflict of interest, $M$. Demkow - proctor in Medtronic.

\section{References}

1. Verheugt CL, Uiterwaal C, van der Velde ET, et al. Mortality in adult congenital heart disease. Eur Heart J 2010; 31: 1220-9.

2. Warnes CA, Williams RG, Bashore TM, et al. ACC/AHA 2008 Guidelines for the management of adults with congenital 
heart disease: executive summary. J Am Coll Cardiol 2008; 52: 1890-947.

3. Homann M, Haehnel JC, Mendler N, et al. Reconstruction of the RVOT with valved biological conduits: 25 years experience with allografts and xenografts. Eur J Cardiothorac Surg 2000; 17: 624-30.

4. Dearani JA, Danielson GK, Puga FJ, et al. Late follow-up of 1095 patients undergoing operation for complex congenital heart disease utilizing pulmonary ventricle to pulmonary artery conduits. Ann Thorac Surg 2003; 75: 399-410.

5. Boethig D, Goerler H, Westhoff-Bleck M, et al. Evaluation of 188 consecutive homografts implanted in pulmonary position after 20 years. Eur J Cardiothorac Surg 2007; 32: 133-41.

6. Lindberg HL, Saatvedt K, Seem E, et al. Single-center 50 years' experience with surgical management of tetralogy of Fallot. Eur J Cardiothorac Surg 2011; 40: 538-42.

7. Shimazaki Y, Blackstone EH, Kirklin JW. The natural history of isolated congenital pulmonary valve incompetence - surgical implications. Thorac Cardiovasc Surg 1984; 32: 257-9.

8. Bouzas B, Kilner PJ, Gatzoulis MA. Pulmonary regurgitation: not a benign lesion. Eur Heart J 2005; 26: 433-9.

9. Shin YR, Jung JW, Kim NK, et al. Factors associated with progression of right ventricular enlargement and dysfunction after repair of tetralogy of Fallot based on serial cardiac magnetic resonance imaging. Eur J Cardiothoracic Surg 2016; 50: 464-9.

10. Tretter JT, Friedberg MK, Wald RM, McElhinney DB. Defining and refining indications for transcatheter pulmonary valve replacement in patients with repaired tetralogy of Fallot: contributions from anatomical and functional imaging. Int J Cardiol 2016; 221: 916-25.

11. Baumgartner H, Bonhoeffer P, De Groot NMS, et al. ESC Guidelines for the management of grown-up congenital heart disease (new version 2010). Eur Heart J 2010; 31: 2915-57.

12. Silversides CK, Kiess M, Beauchesne L, et al. Canadian Cardiovascular Society 2009 Consensus Conference on the management of adults with congenital heart disease: outflow tract obstruction, coarctation of the aorta, tetralogy of Fallot, Ebstein anomaly and Marfan's syndrome. Canadian J Cardiol 2010; 26: E80-97.

13. Geva T. Indications for pulmonary valve replacement in repaired tetralogy of fallot the quest continues. Circulation 2013; 128: 1855-7.

14. Kanter KR, Budde JM, Parks WJ, et al. One hundred pulmonary valve replacements in children after relief of right ventricular outflow tract obstruction. Ann Thoracic Surg 2002; 73: 1801-6.

15. Lange R, Weipert J, Homann M, et al. Performance of allografts and xenografts for right ventricular outflow tract reconstruction. Ann Thoracic Surg 2001; 71: S365-7.

16. Bonhoeffer P, Boudjemline Y, Saliba Z, et al. Percutaneous replacement of pulmonary valve in a right-ventricle to pulmonary-artery prosthetic conduit with valve dysfunction. Lancet 2000; 356: 1403-5.

17. Medtronic Inc. Indications, Contraindications, Warnings, Precautions and Adverse Events: MelodyVR Transcatheter PulmonaryValve and EnsembleVR Transcatheter Delivery System. Medtronic, IncInternational Section, 2009.2009: http://www.medtronic. com/intl/melody/melody_warn.html.

18. Garay F, Webb J, Hijazi ZM. Percutaneous replacement of pulmonary valve using the Edwards-Cribier percutaneous heart valve: first report in a human patient. Catheter Cardiovasc Interv 2006; 67: 659-62.

19. http://www.edwards.com/devices/heart-valves/transcatheter-sapien-xt-valve-pulmonic.
20. Hascoet S, Acar P, Boudjemline Y. Transcatheter pulmonary valvulation: current indications and available devices. Arch Cardiovasc Dis 2014; 107: 625-34.

21. Kenny D, Hijazi ZM, Kar S, et al. Percutaneous implantation of the Edwards SAPIEN transcatheter heart valve for conduit failure in the pulmonary position early phase 1 results from an international multicenter clinical trial. J Am Coll Cardiol 2011; 58: 2248-56.

22. Demkow M, Ruzyllo W, Biernacka EK, et al. Transcatheter implantation of the biological Sapien Edwards valve in the pulmonary position - first experiences. Post Kardiol Interw 2011; 7: 111-5.

23. Momenah TS, El Oakley R, Al Najashi K, et al. Extended application of percutaneous pulmonary valve implantation. J Am Coll Cardiol 2009; 53: 1859-63.

24. Demkow M, Ruzyllo W, Biernacka EK, et al. Percutaneous Edwards SAPIEN (TM) valve implantation for significant pulmonary regurgitation after previous surgical repair with a right ventricular outflow patch. Catheter Cardiovasc Interv 2014; 83: 474-81.

25. Schievano S, Migliavacca F, Coats L, et al. Percutaneous pulmonary valve implantation based on rapid prototyping of right ventricular outflow tract and pulmonary trunk from MR data. Radiology 2007; 242: 490-7.

26. Lurz P, Philipp B, Taylor AM. Percutaneous pulmonary valve implantation: an up-date. Expert Rev Cardiovasc Ther 2009; 7: 823-33.

27. Demkow M, Biernacka EK, Spiewak M, et al. Percutaneous pulmonary valve implantation preceded by routine presenting with a bare metal stent. Catheter Cardiovasc Interv 2011; 77: 381-9.

28. Cheatham JP, Hellenbrand WE, Zahn EM, et al. Clinical and hemodynamic outcomes up to 7 years after transcatheter pulmonary valve replacement in the US Melody Valve Investigational Device Exemption Trial. Circulation 2015; 131: 1960-70.

29. Borik S, Crean A, Horlick E, et al. Percutaneous pulmonary valve implantation: 5 years of follow-up does age influence outcomes? Circulation Cardiovasc Interv 2015; 8: e001745.

30. Armstrong AK, Balzer DT, Cabalka AK, et al. One-year follow-up of the melody transcatheter pulmonary valve multicenter post-approval study. JACC Cardiovasc Interv 2014; 7: 1254-62.

31. Butera G, Milanesi O, Spadoni I, et al. Melody transcatheter pulmonary valve implantation. Results from the registry of the Italian Society of Pediatric Cardiology. Catheter Cardiovasc Interv 2013; 81: 310-6.

32. Biernacka EK, Ruzyllo W, Demkow M, et al. Transcatheter pulmonary valve implantation in patients with right ventricular outflow tract dysfunction: early and mid-term results. I Invasive Cardiol 2015; 27: E82-9.

33. Lurz P, Nordmeyer J, Khambadkone S, et al. Functional outcome early and late (one year) after percutaneous pulmonary valve implantation as assessed by magnetic resonance imaging and exercise testing. Eur Heart J 2010; 31: 930-0.

34. Haas NA, Moysich A, Neudorf U, et al. Percutaneous implantation of the Edwards SAPIEN((TM)) pulmonic valve: initial results in the first 22 patients. Clin Research Cardiol 2013; 102: 119-28.

35. Morray BH, McElhinney DB, Cheatham JP, et al. Risk of coronary artery compression among patients referred for transcatheter pulmonary valve implantation: a multicenter experience. Circulation Cardiovasc Interv 2013; 6: 535-42.

36. McElhinney DB, Cheatham JP, Jones TK, et al. Stent fracture, valve dysfunction, and right ventricular outflow tract reintervention after transcatheter pulmonary valve implantation patient-related and procedural risk factors in the US Melody Valve Trial. Circ Cardiovasc Interv 2011; 4: 602-14. 
37. Jones TK, Rome JJ, Armstrong AK, et al. Transcatheter pulmonary valve replacement reduces tricuspid regurgitation in patients with right ventricular volume/pressure overload (vol 68, pg 1525, 2016). J Am Coll Cardiol 2016; 68: 1525-35.

38. Cardoso R, Ansari M, Garcia D, et al. Prestenting for prevention of melody valve stent fractures: a systematic review and metaanalysis. Catheter Cardiovasc Interv 2016; 87: 534-9.

39. Uebing A, Rigby ML. The problem of infective endocarditis after transcatheter pulmonary valve implantation. Heart 2015; 101: 749-51.

40. Van Dijck I, Budts W, Cools B, et al. Infective endocarditis of a transcatheter pulmonary valve in comparison with surgical implants. Heart 2015; 101: 788-93.

41. Malekzadeh-Milani S, Ladouceur M, Patel M, et al. Incidence and predictors of Melody (R) valve endocarditis: a prospective study. Arch Cardiovasc Dis 2015; 108: 97-106.

42. McElhinney DB, Benson LN, Eicken A, et al. Infective endocarditis after transcatheter pulmonary valve replacement using the melody valve: combined results of 3 prospective North American and European studies. Circ Cardiovasc Interv 2013; 6: 292-300.

43. Jalal Z, Galmiche L, Beloin C, Boudjemline Y. Impact of percutaneous pulmonary valve implantation procedural steps on leaflets histology and mechanical behaviour: an in vitro study. Arch Cardiovasc Dis 2016; 109: 465-75.

44. Jalal Z, Galmiche L, Lebeaux D, et al. Selective propensity of bovine jugular vein material to bacterial adhesions: an in-vitro study. Int J Cardiol 2015; 198: 201-5.

45. Patel M, Iserin L, Bonnet D, Boudjemline Y. Atypical malignant late infective endocarditis of Melody valve. J Thoracic Cardiovasc Surg 2012; 143: E32-5.

46. Ruzyllo W, Wlodarska EK, Demkow M, et al. Transvascular pulmonary valve implantation - early results of the first Polish experience. Post Kardiol Interw 2009; 5: 7-17.

47. Biernacka EK, Piotrowicz E, Fronczak A, et al. Influence of percutaneous pulmonary valve implantation on exercise capacity: which group of patients benefits most from the intervention? Cardiol J 2015; 22: 343-50.

48. Boudjemline $\mathrm{Y}$, Legendre $\mathrm{A}$, Ladouceur $\mathrm{M}$, et al. Branch pulmonary artery jailing with a bare metal stent to anchor a transcatheter pulmonary valve in patients with patched large right ventricular outflow tract. Circ Cardiovasc Interv 2012; 5: E22-5.

49. Schievano S, Taylor AM, Capelli C, et al. First-in-man implantation of a novel percutaneous valve: a new approach to medical device development. Eurointervention 2010; 5: 745-50.

50. Benson LN. One year outcomes from the early feasibility study of the Harmony transcatheter pulmonary valve. TCT 2016.

51. Boudjemline Y, Agnoletti G, Bonnet D, et al. Percutaneous pulmonary valve replacement in a large right ventricular outflow tract - an experimental study. J Am Coll Cardiol 2004; 43: 1082-7.

52. Sosnowski C, Matella T, Fogg L, et al. Hybrid pulmonary artery plication followed by transcatheter pulmonary valve replacement: comparison with surgical PVR. Catheter Cardiovasc Interv 2016; 88: 804-10.

53. Phillips ABM, Nevin P, Shah A, et al. Development of a novel hybrid strategy for transcatheter pulmonary valve placement in patients following transannular patch repair of tetralogy of Fallot. Catheter Cardiovasc Interv 2016; 87: 403-10. 